\title{
Optimization of the Replenishment Strategy for the Supplier Based on Genetic Algorithm
}

\author{
Ke Zhu \\ School of Business, University of Shanghai for Science and Technology \\ 334 Jun Gong Road, Shanghai 200090, China \\ E-mail: zkchwd@126.com \\ Hengshan Wang \\ School of Business, University of Shanghai for Science and Technology \\ 334 Jun Gong Road, Shanghai 200090, China \\ Yuanyuan Kong \\ School of Business, University of Shanghai for Science and Technology \\ 334 Jun Gong Road, Shanghai 200090, China \\ Sheng Li \\ School of Business, University of Shanghai for Science and Technology \\ 334 Jun Gong Road, Shanghai 200090, China
}

The research is financed by Shanghai Key Discipline of Management Science and Engineering. No. S30504 (ponsoring information)

\begin{abstract}
In the supply chain management, the supplier can reduce its total cost by providing price discounts to restrict the retailers' replenishment intervals to multiples of a common replenishment interval. In order to accomplish this purpose, supplier often determined a price discount that all the retailers can accept. After the cost of the supplier was further considered, a better price discount was designed, which can meet all the retailers' requirements to maximize their benefits. And a new supplier's minimization problem model based on stackelberg game was designed also. Then a genetic algorithm is used to solve the supplier's replenishment model. Experiment results of the genetic algorithm demonstrated the feasibility and the effectiveness of the strategy.
\end{abstract}

Keywords: Common replenishment interval, Price discount, Genetic Algorithm

\section{Introduction}

In the supply chain management, more and more enterprises are aware of the importance of cooperation. However, different enterprises belong to different economic entity, so they tend to focus on their own interests rather than the interests of the whole supply chain, which lead to the cooperation more difficulty. Considering that, it's necessary for us to design a mechanism to enhance cooperation between different enterprises. Price discount as a model for enhancing cooperation has been raised by Crowther as early as 1964. He argued that, if suppliers afford price discount to retailers, the retailer's quantity of purchase will be larger than their economic order quantity. And this mode increase revenue of suppliers, at the same time inflate costs of retailers. However, Crowther had not established model for this theory. Based on the study of Crowther, Dolan (1987) established a model and give the order strategies in the case of the lowest whole system cost for suppliers and retailers from perspective of retailers. Monahall (1984) studied the problem of optimal discount from perspective of suppliers for the first time. Lu and Viswanathan deal with optimization of the integrated inventory problem based on the willingness of cooperation for suppliers and retailers. 
The paper aims at analyzing process of ordering goods based on two-echelon supply chain system which consists of one-supplier and multi-retailer. This system adopts the mechanism with common replenishment interval, suggests the supplier offer price discounts for retailers selectively. These tactics reduce the cost of replenishment to retailers, so we can get further improvement on the replenishment decision-making. In this paper, we establish the optimal replenishment model from the perspective of supplier. Price discounts strategy of supplier could be solved by this model. Satisfying results can be getted by the Genetic Algorithm which has adaptive search characteristic. By analyzed the calculation result, the model is proved to be effective in reducing the cost of supplier and the whole supply chain to some extent.

\section{Problem description}

Consider a integrated supply chain with one-supplier and multi-retailer. The retailer demand information about next $\mathrm{T}$ intervals is transferred to supplier through the Internet. As the leader of the stackelberg game, the supplier determines the retailers' replenishment strategy on the basis of the inventory and demand information provided by retailers. This replenishment strategy solved many problems of supplier and retailers, for example, how long of the common replenishment interval, the time to replenish goods, whether the supplier should provide a price discount before the time of replenishment etc. The purpose of the study is to set up a new model to minimize supplier's replenishment cost and reduce retailers' ordering and holding cost as much as possible, which could optimize the whole system.

\section{Problem modeling}

\subsection{Assumption and notation}

We consider a two-echelon supply chain which consists of one supplier and multi-retailer with a single product. To develop the proposed model, the following assumptions and notations are used:

Assumptions

1. The demand rate of the retailers is known and constant.

2. The supplier can meet all the retailers' demand and the lead time is zero.

3. As the the leader of the stackelberg game, the supplier fix the common replenishment interval (such as every week, every month etc).

4. Before the common replenishment interval strategy is implemented, the optimal replenishment interval follows the economic order quantity model.

5. After the common replenishment interval strategy is implemented, the supplier offer the price discounts to certain selected retailers.

Notation

$\mathrm{m}$ the number of the retailers

d the price discounting rate provided by supplier

$\mathrm{P} \quad$ per unit price to the retailer

$h_{i} \quad$ per unit holding cost per time unit for retailer $\mathrm{i}$

$D_{i} \quad$ demand rate for retailer i

$K_{i} \quad$ ordering cost per order for retailer i

$T_{0} \quad$ common replenishment interval

$\mathrm{X}$ the set of common replenishment interval

$A_{\text {s }} \quad$ the setup cost incurred by supplier for processing the entire order

$A_{i} \quad$ the setup cost incurred by supplier for processing a specific order from retailer $\mathrm{i}$

$A_{s i} \quad$ the delivery cost incurred by supplier for processing a specific order from retailer $\mathrm{i}$

$Z_{i} \quad$ the lowest price discounting rate acceptable to retailer i

$t_{i}^{U} \quad$ the optimal replenishment interval corresponding to the EOQ for retailer i

$t_{i}^{c} \quad$ after the common replenishment interval strategy is implemented, the replenishment interval for retailer $\mathrm{i}$

3.2 Before the common replenishment interval strategy is implemented

For retailer i, following the economic order quantity (EOQ) model (Banerjee, 1988), the replenishment interval is given by $t_{i}^{U}=\sqrt{2 K_{i} / h_{i} D_{i}}$, the sum of ordering and holding cost can be expressed as

$$
g_{i}^{U}=\frac{K_{i}}{t_{i}^{U}}+\frac{1}{2} h_{i} D_{i} t_{i}^{U}=\sqrt{2 K_{i} h_{i} D_{i}}
$$


and the total cost can be expressed as $C_{i}^{U}=P D_{i}+g_{i}^{U}$. Correspondingly the supplier's ordering and delivery cost for retailer i can be written as $g_{0}^{U}=\sum_{i=1}^{m}\left(A+A_{s i}\right) / t_{i}^{U}$.

\subsection{After the common replenishment interval strategy is implemented}

When the strategy is implemented, the supplier will provide price discounts to restrict the retailers' replenishment intervals to a common replenishment interval with the purpose of reducing its total replenishment costs. If the supplier provides price discount for the retailer $i$, the optimal replenishment interval of the retailer $i$ is

$$
t_{i}^{c}=n_{i} T_{0}, \text { where } n_{i} \geq 1 \text {, and integer, } T_{0} \in X
$$

Otherwise, its value is the same as the replenishment interval of EOQ.

Correspondingly, the sum of order and holding $\operatorname{cost} g_{i}^{C}$, and total $\operatorname{cost} C_{i}^{C}$ for retailer $\mathrm{i}$ (who accept the price discount) are given by

$$
\begin{aligned}
g_{i}^{c} & =\frac{K_{i}}{n_{i} T_{0}}+\frac{1}{2} h_{i} D_{i} n_{i} T_{0} \\
C_{i}^{C} & =(1-d) P D_{i}+g_{i}^{c}
\end{aligned}
$$

where $g_{i}^{c}$ is convex with respect to $n_{i}$, because of

$$
\begin{aligned}
& \frac{\partial g_{i}^{c}}{\partial n_{i}}=\frac{1}{2} h_{i} D_{i} n_{i}-\frac{K_{i}}{n_{i}^{2} T_{0}} \\
& \frac{\partial^{2} g_{i}^{c}}{\partial n_{i}{ }^{2}}=\frac{2 K_{i}}{n_{i}^{3} T_{0}}>0
\end{aligned}
$$

From $\partial g_{i}^{c} / \partial n_{i}=0$, we obtain a unique root $n^{*}$ that minimize $g_{i}^{c}$ and $C_{i}^{c}$. And $n^{*}$ satisfies

$$
n^{*}\left(n^{*}-1\right) \leq \frac{2 K_{i}}{h_{i} D_{i} T_{0}^{2}} \leq n^{*}\left(n^{*}+1\right)
$$

In the case of the common replenishment interval strategy, if the retailer i accept the price discount, the total cost for retailer i must be smaller than those without price discount. In the paper, the retailer will accept the price discount if it can save $\mathrm{S} \%$ of their total cost. So the price discounting rate should satisfy

$$
d P+\frac{K_{i}(1-S)}{D_{i} t_{i}^{U}}+\frac{1}{2} h_{i}(1-S) D_{i} t_{i}^{U} \geq \frac{K_{i}}{D_{i} n_{i} T_{0}}+\frac{1}{2} h_{i} n_{i} T_{0}
$$

After rearranging the terms in (5), we thus get

$$
d \geq \frac{K_{i}}{P D_{i}}\left(\frac{1}{n_{i} T_{0}}-\frac{(1-S)}{t_{i}^{U}}\right)+\frac{1}{2 P} h_{i}\left[n_{i} T_{0}-(1-S) t_{i}^{U}\right]
$$

From (6), we can get the lowest price discounting rate acceptable to retailer i $Z_{i}$

$$
Z_{i}=\frac{K_{i}}{P D_{i}}\left(\frac{1}{n_{i} T_{0}}-\frac{(1-S)}{t_{i}^{U}}\right)+\frac{1}{2 P} h_{i}\left[n_{i} T_{0}-(1-S) t_{i}^{U}\right]
$$

As the leader, the supplier will offer price discounts to certain selected retailers to minimize its total replenishment cost. For the retailer, if it is offered price discount, its replenishment interval will be a multiple of $T_{0}$, its sum of ordering and holding cost and total cost should be calculated following Eq.(2) and Eq.(3). Otherwise these ones should be calculated following the EOQ model. According to above, the supplier's minimization problem can be rewritten as

$$
\begin{gathered}
g_{0}^{C}=\frac{A_{s}}{T_{0}}+\sum_{i=1}^{m}\left(\frac{A_{i}+A_{s i}}{t_{i}^{U}}\right)+\sum_{i=1}^{m}\left[\left(d P D_{i}+\frac{A_{i}}{n_{i} T_{0}}-\frac{A_{i}+A_{s i}}{t_{i}^{U}}\right) y_{i}\right] \\
\text { s.t. } T_{0} \in X, \quad d \geq Z_{i}, \quad n_{i} \geq 1 \text { and integer, } \mathrm{i}=1, \cdots, \mathrm{m} \\
y_{i}= \begin{cases}1, & \text { offer price discount } \\
0, & \text { otherwise }\end{cases}
\end{gathered}
$$

\section{Genetic algorithm implementation}

The process of biological evolution is mainly accomplished through the crossover operator and the mutation 
operator of chromosomes. Correspondingly, Genetic Algorithm is a high-efficiency method by simulating the process of the biological evolution to search for the optimal solution. And It could apply some genetic operators to act on the population $\mathrm{P}(\mathrm{t})$, then obtain newer population $\mathrm{P}(\mathrm{t}+1)$ by using some measures of fitness. In the next subsections, we will describe the steps required to solve the model given in Eq.(8) by a genetic algorithm.

\subsection{Chromosome coding}

Encoding is the first step of developing a Genetic Algorithm. In the process of searching for the optimal solution, the traditional coding method is to encode the problem's variables as a binary string or a decimal string called chromosome. In this paper, because the values of decision variables $\left(y_{i}\right)$ are 0 or 1 , the binary coding is applied to generate $\mathrm{N}$ chromosomes randomiy represented by a string of $\mathrm{m}$ binary digits, as the initial population. After a stopping criterion is satisfied, a final population will be available. According to the value of the final population, we can get the optimal replenishment decision of the vendor. For example, when $m=10$, the set $\{1,0,0,1,0,1$, $0,1,0,0\}$ represent that vendor would offer price discount to retailer 1 , retailer 4 , retailer 6 and retailer 8 .

\subsection{Fitness evaluation}

In the Genetic Algorithm, each individual in the current population is evaluated only by the fitness, not using any external information. The probability of survival of any individual is determined by its fitness. And the population evolves by the way of the fitter individuals overtaking the less fit ones. In order to calculate the probability of survival of any individual correctly, the fitness value of any individual must be non-negative. Besides, the value of objective function in Eq.(8) is always non-negative, and our aim is to find out the minimum value of the objective function. For this reason, the fitness function can be expressed as follows $\mathrm{F}(\mathrm{X})=C_{\max }-\mathrm{f}$ $(\mathrm{X})$, where $C_{\text {max }}$ is a relatively larger number specified in advance.

\subsection{Selection}

The algorithm use the roulette wheel selection. Several rounds of choice are required to select individuals to go into the next generation. A new random number described by 0 or 1 can be created in each round, as the pointers decide the selected individuals. The selection operator is used for filtering the initial population.

\subsection{Crossover}

In this paper, a method of one-point crossover is used to select a cut point $\mathrm{K}$ in the interval [1, $\mathrm{m}-1]$ randomly, where $\mathrm{m}$ is the number of genes of population. The cut point divides the chromosome into two disjoint parts. Then the crossover creates a offspring by exchanging parts of the parent chromosomes with the step size 2 .

\subsection{Mutation}

In order to avoid the answer becoming trapped in local optima, mutation will arise with a very small probability. Let's designate the loci of chromosomes as change point with the mutation probability $P_{m}=0.02$. Then each gene of the change point is mutated over the integers from 0 to 1.

\section{Numerical example}

In this section, we suppose that: the number of the retailers is $m=20$, per unit price to the retailer is $p=\$ 1$, the unit holding cost of product at unit time is $h_{i}=\$ 0.1$ for every retailer. The demand and the cost for per ordering are given in table 1. In order to calculate easily, we assume that different retailers have the same setup cost and transportation cost supported by supplier. Each parameter of supplier: $A_{s}=\$ 500, A_{s i}=\$ 300, A_{i}=\$ 200$, the set of common replenishment interval is $\mathrm{X}=\{1,7,14,30,60,90\}$. After the common replenishment interval strategy is implemented, the retailer will accept the price discount if it can save $\mathrm{S}=10 \%$ of their total cost.

Insert Table 1 here.

Based on the data from the above, we can derive that if price discounts provided for every retailer are the same (Viswanathan, 2001), the minimum replenishment cost of supplier is $\$ 134544$, the ordering and holding cost of the whole system is $\$ 582691$. In this paper, we use the model established to solve this problem. Then numerical results are calculated by genetic algorithm. Each initial parameter of genetic algorithm: the population size is $\mathrm{M}$ $=20$, the iterations is MaxGeneration $=1000$. After many experiments, we can draw a conclusion that when the probability of crossover is 0.8 , and the probability of mutation is 0.08 , genetic algorithm has a better convergence. We find that the replenishment cost of supplier can reach minimum $\$ 126183$ when $T_{0}=14$, and the ordering and holding cost of the whole system is $\$ 574074$. Correspondingly, supplier's percentage savings, retailers' percentage savings and system percentage savings are $6.2 \%, 0.06 \%$ and $1.5 \%$, respectively. Figure 1 shows the relationship between iterations and best individual of population of every generation corresponding replenishment cost of supplier during the process of calculation of genetic algorithm. After 300 iterations, the global approximate optimal value of the replenishment cost of supplier can be obtained. From the computational process and the results, this strategy can reduce both the supplier's cost and the retailer's ordering and holding 
cost furtherly, which can be used for guiding enterprise to increase profits and reduce costs.

\section{Conclusion}

By a few calculations, we can come to the conclusion that: this model can be used more effectively either when we solve the ordering problem with lots of retailers, or when the condition about ordering cost (requirement, the optimal cycle of ordering etc) of the retailers are very different with each other. In reality, for large supplier, the proposed method in this paper is effective in both strengthening cooperation between supplier and retailers, and making replenishment decision in short time. Therefore, this problem is worth to carry out by more study and researches.

\section{References}

Banerjee, A. (1986). A joint economic lot size model for purchaser and vendor. Decision Science, 17, $292-311$

Giannoccaro, I., \& Pontrandolfo, P. (2004). Supply chain coordination by revenue sharing contracts. International Journal of Production Economics, 89, 131-139

Goyal, S. K. (1988). A joint economic lot-size model for purchaser and vendor: A comment. Decision Sciences, $19,236-241$

Hoque, M. A. (2006). An optimal solution technique for the joint replenishment problem with storage and transport capacities and budget constraints. European Journal of Operational Research, 175, 1033-1042

James, Hill., Michael, R., \& Galbret, h. (2008). A heuristic for single-warehouse multi retailer supply chains with all-unit $\mathrm{t}$ ransportation cost discount. European Journal of Operational Research, 187, 473-482

Moon, I. K., \& Cha, B. C. (2006). The joint replenishment problem with resource restriction. European Journal of Operational Research, 173, 190-198

Munson, C. L., \& Rosenblatt, M. J. (2001). Coordinating a three-level supply chain with quantity discount. IIE Transactions, 33, 371-384

Qin, Y., Tang, H., \& Guo, C. (2007). Channel coordination and volume discounts with price-sensitive demand. International Journal of Production Economics, 105, 43-53

Viswanathan, S., \& Piplani, R. (2001). Coordinating supply chain inventories through common replenishment epochs. European Journal of Operational Research, 129, 277-286

Wu, K. S., Ouyang, L. Y., \& Yang, C. T. (2006). An optimal replenishment policy for non-instantaneous deteriorating items with stock-dependent demand and partial backlogging. International Journal of Production Economics, 101, 369-384

Table 1. The Retailers' demand and the cost for per ordering

\begin{tabular}{c|c|c|c|c|c|c|c|c|c|c}
\hline Retailer i & 1 & 2 & 3 & 4 & 5 & 6 & 7 & 8 & 9 & 10 \\
\hline Ordering cost $K_{i}(\$)$ & 100 & 1000 & 100 & 5000 & 100 & 2000 & 100 & 5000 & 100 & 1000 \\
\hline $\begin{array}{c}\text { Annual demand } \\
\text { (in millions) }\end{array}$ & 1 & 2 & 3 & 4 & 5 & 6 & 7 & 8 & 9 & 10 \\
\hline Retailer i & 11 & 12 & 13 & 14 & 15 & 16 & 17 & 18 & 19 & 20 \\
\hline Ordering cost $K_{i}(\$)$ & 50 & 50 & 150 & 100 & 500 & 500 & 500 & 1000 & 5000 & 3000 \\
\hline $\begin{array}{c}\text { Annual demand } \\
\text { (in millions) }\end{array}$ & 2 & 0.5 & 1 & 0.5 & 2 & 1 & 0.5 & 0.5 & 2 & 0.5 \\
\hline
\end{tabular}

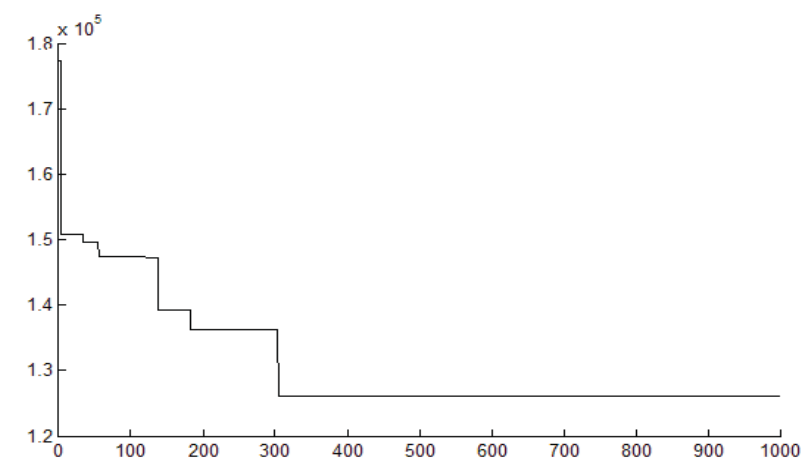

Figure 1. The convergence path of supplier's replenishment cost 